\section{Niels Bohr's long legacy}

WERE Niels Bohr still alive - he died in 1962 - he would probably find some way to rescue the Copenhagen-based institute that now bears his name from its current doldrums.

Bohr founded the institute in 1921, the year before he won a Nobel prize in physics (a feat that was repeated by his son, Aage, in 1975). But his influence on Danish physics did not stop there. He was also instrumental in guiding the Forskningscenter Ris $\varnothing$ on a path of basic energy research instead of pure nuclear physics, a move that allowed it to survive when Denmark later decided not to build any nuclear power plants.

As if that is not enough, Bohr's collaboration with the Russian physicist Lev Landau established the basis for a wideranging scientific exchange between Denmark and the Soviet Union. Even during the difficult days in the early 1980 s, some 20 Soviet physicists a year were visiting Denmark for up to several months. Next year, 25 Soviet researchers are due in Copenhagen to celebrate the eighteeth anniversary of Landau's birth.

Bohr can also be credited with the special status that the institute has enjoyed with regard to government funding, as well as with the tendency of Danish industry to start to pick up the slack as government funds start to falter. Danish physics has responded by achieving significantly more scientific citations per physics paper than Great Britain, West Germany and France, according to a British Royal Society study.

But, according to director Knud Hansen, the Bohr Institute has come upon hard times in recent years. Despite quite a few permanent positions for researchers not required to teach, Hansen says that the university "budget model" has "no room left" for research institutions like his.

The addition of five more five-year research professorships is only a stopgap, according to Hansen. "It's like a man drowning in the middle of the Atlantic clinging to a piece of driftwood". If something does not float by soon, Hansen says, the high standards of the institute are at risk. Will Bohr's posthumous influence, which is still strongly felt in the corridors of power, be enough?
Nordic collaboration

LOCATED in one wing of the Niels Bohr Institute, NORDITA, the Nordic Institute for Theoretical Physics, is "the most institutionalized scientific collaboration" among the Scandinavian countries, according to its director, Allan Mackintosh. Its budget of DKr15 million for 1987 is provided on a GDP basis by the five Nordic countries (including Iceland). And its undoubted success is attributed in large part to Niels Bohr, who helped to found NORDITA in the late 1950s.

The institute's official purpose is "to further collaboration between the Nordic countries within basic theoretical physics". There are 30 to 40 researchers there at any given time, including 6 full professors, 4 assistant professors and up to 16 Nordic fellows who are resident for two years before returning to their home countries. The institute acts as a focal point for theoretical physics in the Nordic region and as a draw to distinguished visitors from elsewhere. Part of its budget is used to allow visitors to spend a period of time in institutes in the member states.

The institute is funded by the Nordic Council of Ministers and is run by a board composed of physicists from each of the member countries. The board and the director keep a watchful eye on the balance of the staff in terms of their country of origin.

Mackintosh realizes just how lucky he is to be in an institution with a stable budget. NORDITA has even been able to get some sorely needed increases from the member states - for computing, for example. By comparison, the Bohr Institute had to rely on a private donation two years ago to update its Univac computer.

Sheet Program, a joint Danish-Swiss-US project, sent groups led by Dansgaard, Hans Oeschger of Switzerland, and C.C. Langway of the United States to a site in southeast Greenland for three successive summers in the mid-1970s. There they drilled back in time tens of thousands of years, testing the core samples for carbon dioxide content as well as for cosmic dust and oxygen isotopes.

Dansgaard and his international counterparts now have an even more ambitious programme in mind. They would like to set up another drill at "SUMMIT", the highest (and coldest) point in Greenland, and accomplish two tasks. First would be to examine in detail the dust blown in from other land masses that has collected there over the past 1,000 years and which would help in dating climatic changes. Second would be to go back 500,000 years in time - more than was possible at the first site. Dansgaard hopes that the project will be blessed by the European Science Foundation by the end of 1987 . This would help with the fund-raising effort. It is hoped that drilling will begin in summer 1989 . 